\title{
FATAL SUICIDAL POISONING BY CHLOROQUINE IN PRESENCE OF ALCOHOL-AN INTERESTING CASE REPORT
}

\author{
Pallavi Choudhary*, Kanak LataVerma**, Madhulika Sharma***, Adarsh Kumar* \\ *Department of Forensic Medicine and Toxicology, All India Institute of Medical Sciences, \\ Ansari Nagar, New Delhi, India, **Regional Forensic Science Laboratory, Government of \\ National Capital Territory of Delhi, Chankyapuri Delhi, India,***Forensic Science Laboratory, \\ Government of National Capital Territory of Delhi, Rohini, Sector-14, Delhi, India \\ Corresponding Author \\ Prof. Adarsh Kumar, \\ Room no. 315 \\ Department of Forensic medicine \& Toxicology \\ AIIMS, New Delhi- 110029, India \\ Email-dradarshk@yahoo.com \\ Tel: +91-9868438856
}

\section{ABSTRACT}

Objectives: Suicidal and accidental poisoning due to drug overdose is one of the common reason of morbidity and mortality all over the world. Considering such statement, toxicological analysis is become imperative in suicidal, accidental and also in homicidal deaths now a days. In current case dead body of a young male was found at waiting hall of New Delhi Railway station in a cold winter day with a suicide note indicating a failed love affair. Empty strip of chloroquine tablet was recovered from clothing of deceased. Methodology: Analytical and chemical methods used for toxicological investigation comprised of classical chemical tests, Thin Layer Chromatography, High Performance Thin Layer Chromatography \& Gas Chromatography-Mass Spectroscopy. These techniques established the qualitative examination as well as confirmation of the drug in the visceral tissues and blood. Gas Chromatography -Head Space was used to quantify the amount of alcohol in blood. Results: The chloroquine drug was identified in the visceral tissue and blood sample of the deceased. The blood alcohol level in the sample was $30 \mathrm{mg} / 100 \mathrm{ml}$ of blood.

Conclusion: This study discusses various aspects of qualitative identification of chloroquine and quantification of alcohol with the intricacies involved in interpretation of result with special concern for forensic \& legal implications.

Key Words: Chloroquine, Ethyl alcohol, Suicide, High Performance Thin Layer Chromatography, Gas Chromatography-Head space, Gas Chromatography -Mass Spectroscopy 


\section{INTRODUCTION}

Malaria is a disease which is spread throughout the world. An increase of 5 million cases of malaria has been reported in 2016 as compared to 2015.Around 216 million cases were reported in 2016 across 91 countries (Clemessy JL et al. 1996). 45000 deaths were reported worldwide due to malaria in 2016(www.who.int/malaria/publications/w orld-malaria-report2017). Suicidal or homicidal poisoning with drug overdose is one of the common cause of morbidity and mortality in India. Self-poisoning episode continues to risk with the rate being highest in Europe and chloroquine intoxication has been found to be extremely dangerous (Kumar $\mathbf{R}$ et al $\mathbf{2 0 0 5}^{\cdot}$ Literature reveals that chloroquine overdose12-35\% among the highest in clinical toxicology (Gold frank LR 1998). Ingestion of more than $5 \mathrm{gm}$. of chloroquine is apparently a predictor of fatality. Death in such cases is due to cardio toxicity (Clemessy JL et al. 1996). Chloroquine is a 4-aminoquinolein derivative and was synthesized for the first time in Germany and studied under the name Resochin by Bayer Corporation in 1934 (Cooper RG and Magwere T 2008). It was discarded by mistake and rediscovered 10 year later in USA to develop synthetic anti-malarial drugs. This is marked in history as Chloroquine birth as the greatest concentration of scientific talent ever assembled for solving a single medical problem (Torrey EF 1968). It is widely used medicine for the treatment of all forms of malaria (Yonemitsu $\mathrm{K}$ et al 2005, Nothdurft HD \& Kain KC 2017), amoebiasis, rheumatoid arthritis, porphyria (Cooper RG \& Magwere T 2008, Keller $T$ et al 1998). Chloroquine is the most preferred drug of choice for chemo suppression and radical cure of malaria in malarial-endemic communities of the developing countries primarily because it is cheap, rapidly effective and readily available(Adebayo RA et al. 1986, Magwere T et al. 1997). It is also used in the treatment of discoid lupus erythematosus(Sanchez-Chapula JA et al. 2001), autoimmune group of disease(T.A Don Michael et al. 1970) and diabetes(Smith GD et al 1987). Chloroquine has a quinolone ring (Figure 1) like that of quinine and a side chain identical to that of quinacrine and the chloride atom in the seventh position appears to be crucial to its anti-malarial activity.

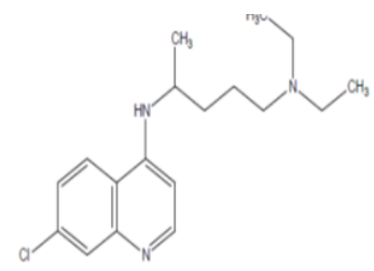

Figure 1: Chemical structure of Chloroquine (Source: Clark' Analysis of Drugs and Poison $3^{\text {rd }}$ edition Pharmaceutical Press 2005)

Chloroquine is a bitter, colorless, dimorphic crystalline powder soluble in water at $\mathrm{pH} 4.5$.It is rapidly and completely absorbed by gastrointestinal tract (Cooper RG \& Magwere T 2008, Keller $T$ et al. 1998, Muhm $M$ et al 1996). There is a very narrow margin between therapeutic and toxic dose of chloroquine (Keller $\mathbf{T}$ et al. 1998).It is also associated with cardiovascular effects including fall in blood pressure, rhythmabnormalities (Sanchez-Chapula JA et al. 2001), bradycardia or ventricular tachycardia, widened QRS complexes, STsegment depression, flattening of $\mathrm{T}$ waves 
and finally ventricular fibrillation and cardiac arrest (Muhm M et al. 1996). It is also associated with retinal toxicity when consumed in long term (Nothdurft HD \&Kain KC 2017).Clinical feature of toxicity also include hypokalemia, convulsion(Phipps C et al. 2011) and respiration depression (Keller $\mathbf{T}$ et al. 1998, Queen HF et al 1999). The various psychiatric manifestations associated with the usage of chloroquine have been described as personality changes, depression, depersonalization, neurotic symptoms and florid psychosis (Mohan D. et al. 1981). The wide spread nature of malaria in tropical and subtropical countries is one of the reasons of chloroquine abuse through self-medication (Adome RO et al.1997).

Ihenacho HNC, Magulike E(2008) reported the abuse of chloroquine among Africans living in malaria-endemic community in Nigeria, in Western Uganda (Mbajiorgu Ejikeme Felix (2010) for suicidal purpose(Adebayo RA 1986) Chloroquine toxicity and over dosage related deaths has also been reported in many American soldiers during their posting in Korea, Vietnam(Frank W. Kiel 1964), and in Asian community also(Frank W. Kiel (1964). In India, cases related with suicidal chloroquine poisoning has also been reported, but it has not been found to be very common (Rodrigues E.J \& Rataboli P.V 2000). The Paris society promoting voluntary suicide recommends chloroquine to its member as a potentially toxic drug, which is easily obtainable over the counter (Stiff G. 1991). Other than chloroquine, ethanol has been reported to be one of the most commonly abused substance in Africa in particular and all around the world in general. The concurrent intake of chloroquine and ethanol is not uncommon in these regions of world especially in subSaharan Africa. Ethanol is one of the most widely abused drugs in spite of the wellknown fact that chronic alcohol ingestion is the major cause of liver disease, leading to abnormal drug metabolism. Ethanol may interact with other drugs and their effect at their site of action. The interaction of ethanol with the oxidative hepatic microsomes drug metabolizing enzyme has been reported to produce adverse clinical effects in the individual. Chloroquine has been reported to potentially modulate the activity of drug metabolizing enzyme and consequently, cause drug-drug interaction (Mbajiorgu Ejikeme Felix 2010). Its combination with other drug may lead to enhancement or inhibition of drug efficiency/toxicity.

\section{Case History}

The dead body of a young, stout male aged 22 years was found lying in waiting hall of New Delhi Railway station on a cold winter day. A suicide note was found near the dead body along with his two bags indicating failed love affair. On suicide note it was written that he is committing suicide and his dead body may be sent to his lover. Thorough search revealed that he belonged to state of Odisha. Further investigation revealed that his lover in Odisha has also committed suicide around same day. Because of interstate coordination and legal ownership of dead body, Post-mortem examination could be conducted after 9 days of recovery of the dead body. At post mortem examination $150 \mathrm{ml}$ of yellowish liquid emitting pungent smell was found in stomach. Doctor who conducted postmortem suggested chloroquine poisoning. Preserved viscera were sent to Forensic 
Science Laboratory (GNCT of Delhi) Rohini, Delhi, India for detection of any poisonous substance or otherwise.

\section{MATERIALS AND METHODS}

Reagents and Apparatus:

Chloroquine phosphate was obtained from Indian Pharmacopeia Commission. The chemicals for digestion and extraction were: Anhydrous Ammonium sulphate, Conc. Acetic acid, Ammonia Sodium tungstate, Chloroform and Methanol of analytical grade and were obtained from MERCK.

The solvent system for thin-layer chromatography was: Benzene/Methanol/Diethyl amine (7.5/1.5/1 by volume) of analytical grade and obtained from MERCK. Dragendorff's spray reagent and Liebermann's solution was prepared according to Clarke. (Clarke, E.G.C 1974)

Extraction procedure (Rao MS (2005): $50 \mathrm{gm}$ of macerated viscera i.e. stomach and intestine, liver, kidney and spleen were treated with $10 \mathrm{gm}$. of Anhydrous Ammonium sulphate and 10 $\mathrm{ml}$ of conc. Acetic acid, then subjected to digestion on a water bath for 3 hours at $100^{\circ} \mathrm{C}$ and further screened using alkaline, acidic and neutral ether extraction by chromatographic and spectrophotometric methods.

One $\mathrm{ml}$ of blood was diluted and treated with a pinch of sodium tungstate and $2 \mathrm{ml}$ of conc. Sulphuric acid. The deproteinised blood was also extracted by the above procedure and then analyzed by TLC, HPTLC and GC/MS.

Distillation procedure (Rao MS (2005): 5 gm. of viscera i.e. stomach and intestine was taken in conical flask then
$5 \mathrm{ml}$ of dilute $\mathrm{HCl}$ was added into it and set over the distillation apparatus. Distillate was collected in volumetric or standard flask. The distillate was analyzed by chemical test for detection of ethyl alcohol.

Colour Tests (Rao MS (2005) (a). Liebermann's test -The preliminary identification of chloroquine drug in the visceral exhibit (stomach, intestine and liver) and blood was done on the basis of Lieberman's color test which was found to be positive. The Lieberman's reagent is an appropriate test for the preliminary examination as it gives intense orange color upon reaction with the extract. (b).Potassium Dichromate test - Potassium dichromate solution was added in distillate then immediately conc. $\mathrm{H}_{2} \mathrm{SO}_{4}$ was added slowly. Presence of bottle green color showed presence of ethyl alcohol in sample.(c)Iodoform crystal test- One drop of sodium hydroxide solution was added in the distillate then solution of iodine was added till brown color appeared, sample was heated till brown color disappeared. The procedure was repeated thrice. Yellow colored hexagonal iodoform crystals showed presence of ethyl alcohol in sample.

Thin layer Chromatography (TLC): $T L C$ is used for the analysis of different complex mixture by the toxicologist/Chemist in different fields worldwide because of its sensitivity of detection in a relatively short time (of less than hours) (Jaiswal A.K 2009). For the present case study preliminary examination of samples was done using TLC plates (silica gel G $60 \mathrm{~F}_{254}$ DC Kiesel gel $60 \mathrm{~F}_{254} \mathrm{CCM}$ Gel silica gel $60 \mathrm{~F}_{254} \mathrm{TLC}$ silica gel $\left.60 \mathrm{~F}_{254}\right)$ which were placed at $105^{\circ} \mathrm{C}$ for $30 \mathrm{~min}$ for activation. The chamber was saturated for $30 \mathrm{~min}$. The 
solvent systems were used as described in method and materials. The developed plates were sprayed with Dragendorff's reagent to visualize the location of chloroquine.

\section{High Performance Thin layer} Chromatography (HPTLC): HPTLC is one of the sophisticated instrumental techniques based on all the qualities of thin layer chromatography with the advantages of minimum sample preparation, automation, scanning full optimization and selective detection. These advancement increases resolution of the compounds to be separated (Attimarad M 2011). Qualitative analysis of Chloroquine carried out on HPTLC (CAMAG Linomat5) equipped with UV detector. Extracted material obtained from viscera, blood and reference standard were spotted on $20 \times 10 \mathrm{~cm}$ pre-coated silica gel 60F254 HPTLC plates(Merck). The plate was developed to height of $5 \mathrm{~cm}$ using Methanol as solvent system.

GasChromatography-Mass-

Spectroscopy (GC-MS): Agilent 6890 GC with Mass Spectrophotometer was used to analyze all the sample. The instrument had Agilent 19091 J-333 HP-5Column packing with5\% phenyl Methyl Siloxane with MSD Detector. The setting of the instrument was Oven Temperature- 300 ${ }^{\circ} \mathrm{C}$, Injection Temperature $-280^{\circ} \mathrm{C}$, Injection volume - $1 \mu \mathrm{L}$, Mode - Split, Carrier Gas - Helium, Flow Rate - 70.9 $\mathrm{ML} / \mathrm{min}$., Detector Temperature - $290^{\circ} \mathrm{C}$. Total run time for a cycle was $25 \mathrm{~min}$. The instrument accesses the various type of international library software (NIST).

Head Space- Gas Chromatography (GC-HS): Worldwide method of choice for qualitative and quantitative analysis of ethanol in biological samples is gas chromatography with flame ionization detector using either a direct injection technique or by headspace sampling. Headspace sampling prevents overloading of column with non-volatile constituent of blood and other biological samples (Kugelberg FC \& Jones AW 2007). For the present case study quantification of ethanol was performed on Perkin Elmer Gas chromatograph (Model Clarius 500) coupled with Head space sampler (HS40/110 trap) equipped with FID detector temp held on $250^{\circ} \mathrm{C}$. The GC column used was ELITE WAX (cross band 5\% Diphenyl, 95\% polysiloxane). Nitrogen gas was at $1 \mathrm{ml} / \mathrm{min}$ flow rate. Hydrogen/Air was at $40 \mathrm{ml} / \mathrm{min}$ and $400 \mathrm{ml} / \mathrm{min}$ flow rate respectively. The column temp was initially held at $45^{\circ} \mathrm{c}$ and final temp $220{ }^{\circ} \mathrm{c}$. Head space parameter: injection temp $80{ }^{\circ} \mathrm{c}$, transfer line temp $130{ }^{0} \mathrm{c}$, oven temp $70{ }^{0} \mathrm{c}$ thermostat time $15 \mathrm{~min}$ injection time $0.08 \mathrm{~min}$, pressurization time $0.5 \mathrm{~min}$. Total cycle time $28 \mathrm{~min}$. Four point calibrators were prepared by diluting ethanol with distilled (Figure 2).

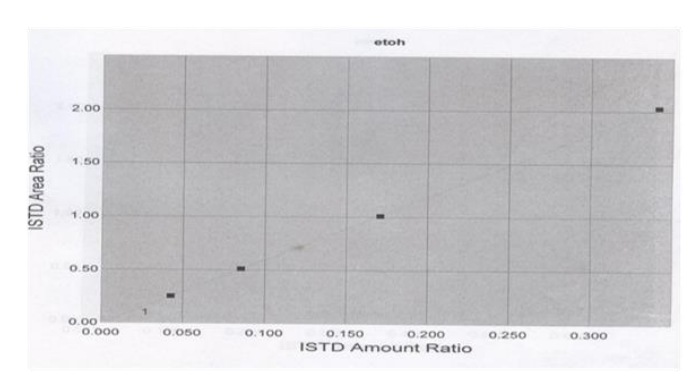

Figure 2: Linearity of Calibration curve for ethanol using GC-HS

The stock internal standard was prepared by diluting $300 \mu \mathrm{l}$ of n-propanol to volume in a $100 \mathrm{ml}$ volumetric flask with distilled water.90 $\mu 1$ of internal standard from the stock solution was added in the $1 \mathrm{ml}$ of each calibrators and 
samples. Stock solutions were stored at $4^{0} \mathrm{c}$.

\section{RESULTS \& DISCUSSION}

The chloroquine drug was identified in the visceral tissue and blood sample of the deceased through classical chemical test and sophisticated analytical methods. The preliminary identification of the drug was done by Liebermann's color test as described before, the appearance of orange color of the test solution which was comparable in intensity and color with that of working standard solution. The blank test was run simultaneously which gave negative result confirming that our chemical test method was devoid of any cross contamination or false positive. The positive chemical test gave us the lead to move for confirmatory test of the target drug through other complimentary techniques like TLC, HPTLC and GC-MS. The TLC was run along with a reference standard procured from Indian Pharmacopeia commission. The chromatographic spot of chloroquine showed colored reaction with Dragondorff reagent and $\mathrm{Rf}$ value identical with that of corresponding reference compound. Further the samples were subjected to HPTLC and confirmation of the presence of chloroquine was done as the dried plate was sprayed by nitrogen gas and subjected in the CAMAG TLC Scanner (Figure 3).

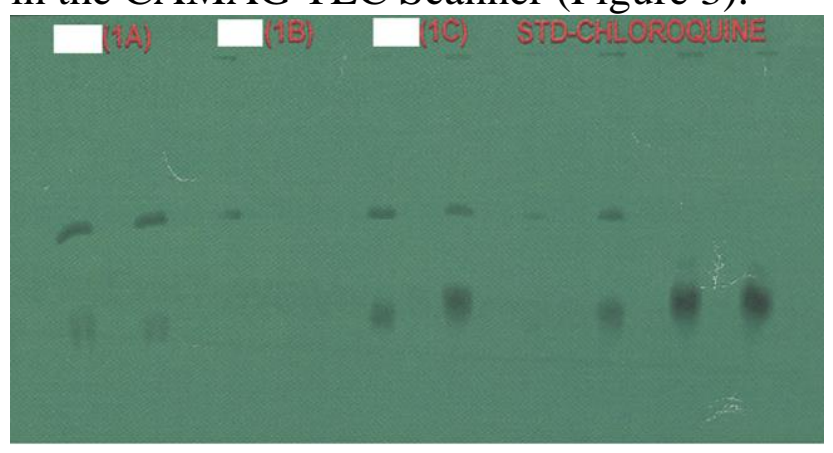

Figure 3: Scanned plate of HPTLC developed in methanol showing clear matching of spots of standard and exhibits

Retention factor of the sample matched with that of standard at 0.52 at $341 \mathrm{~nm}$ and 254 lambda max. (Figure 4\& Figure 5)

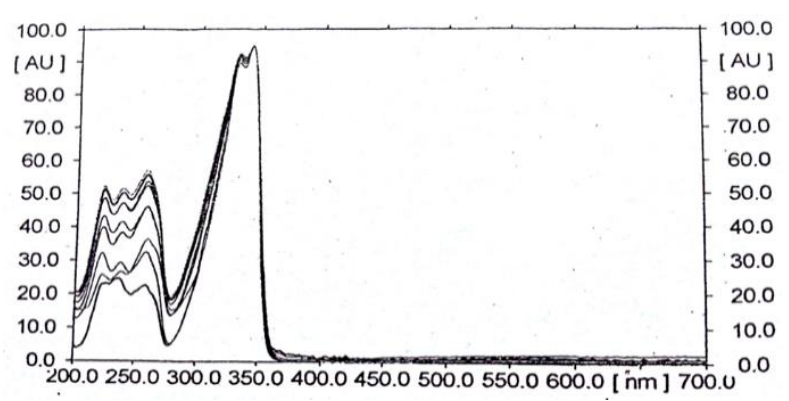

Figure 4: HPTLC chromatogram of the exhibits along with the standard in methanol showing $\mathrm{Rf}$ at $341 \mathrm{~nm} \lambda$ max

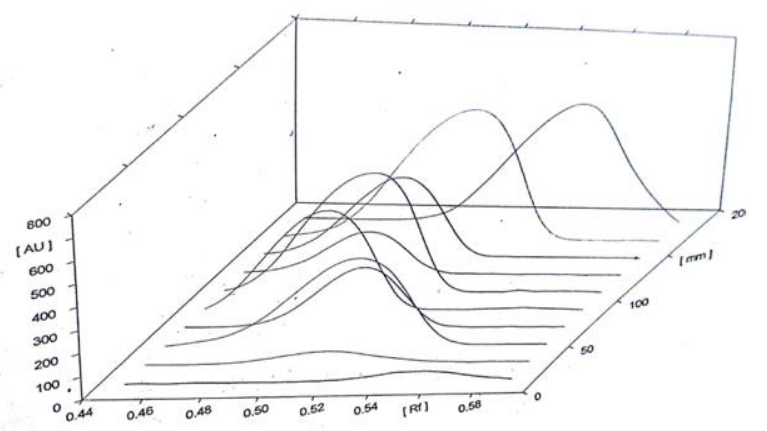

Figure 5: HPTLC Chromatogram of all tracks including sample and standard at $254 \mathrm{~nm} \lambda \max$

The samples were further analyzed by GC-MS which is unique identification and confirmatory technique wherein the compound of interest are confirmed for their presence on the basis of retention time and matching of fragmentation pattern of the target molecule with that of standard compound present in the data base of the instrumental library. In this study presence of chloroquine was confirmed by way of comparison of both 
Retention time (16.915 min.) (Figure 6\&Figure7) and the matching with MS fragmentation.

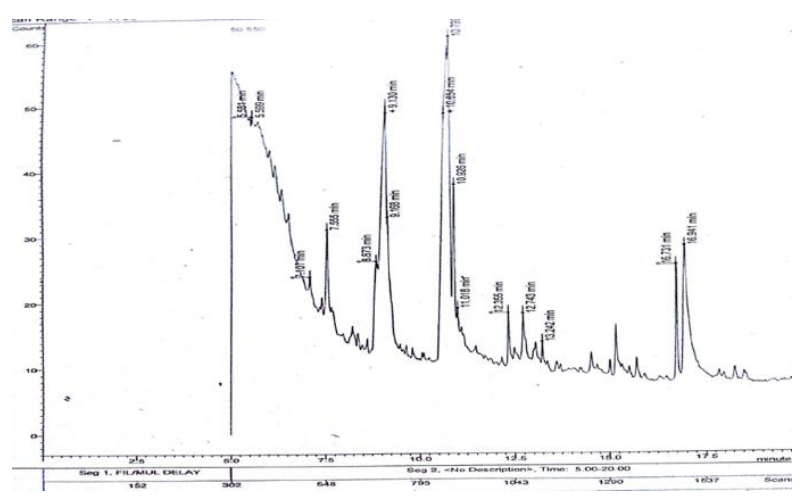

Figure 6: Results of TLC and HPTLC for chloroquine was confirmed by Gas Chromatography technique in the exhibits (stomach and liver)

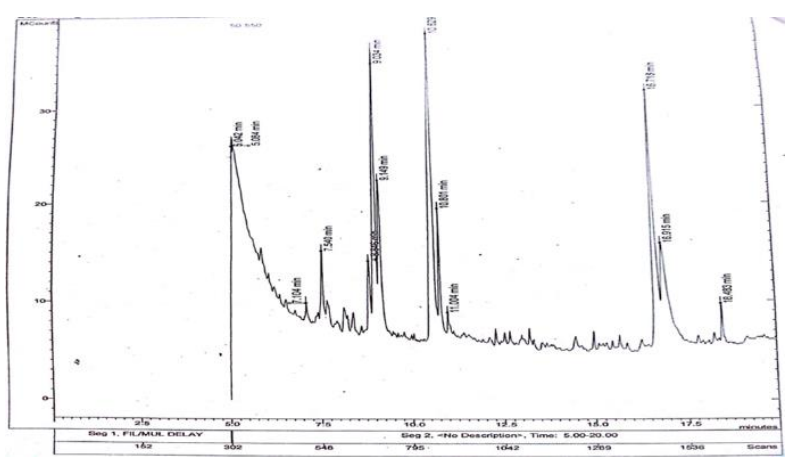

Figure 7 : Results of TLC and HPTLC for chloroquine was confirmed by Gas Chromatography technique in the exhibits (blood)

The peak detected was identified as chloroquine on both retention time and GC-MS spectrum which showed the principle peaks at $\mathrm{m} / \mathrm{z}$ was 247,290 and 320.

The presence of alcohol in the visceral tissue and blood along with the drug was established by quantification of ethyl alcohol in the blood sample through GCHS. The chromatogram produced clearly indicates the presence of ethanol at
Retention time 3.9 min. and blood alcohol level in the sample is quantified as $30.8 \mathrm{mg} / 100 \mathrm{ml}$ of blood (Figure 8 ).

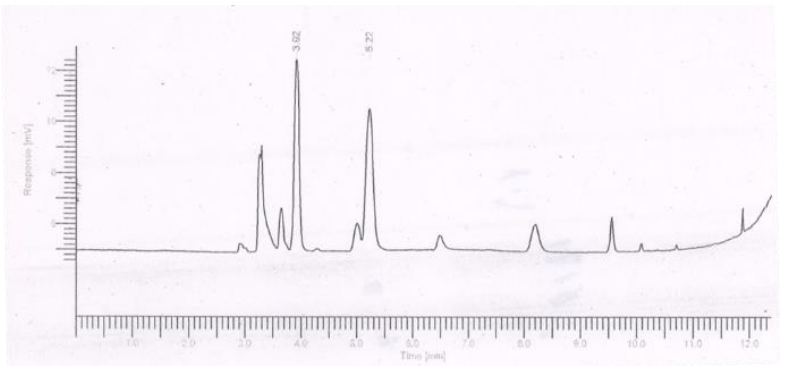

Figure 8: Gas Chromatography-Head Space chromatogram showing positive result for ethanol in exhibit (Blood) at 3.9 min (Retention time)

The $n$ - propanol which is used as an internal standard elutes at Rt $5.2 \mathrm{~min}$. which is indicative of the fact that our method is well in place and the presence of alcohol in the sample is positively established. There has been literature citing a combined intake of chloroquine and alcohol in a suicidal attempt though the quantification of alcohol is not reported (Frank W. Kiel 1964).

Death involving Chloroquine poisoning and its detection by HPLC has been reported by Sarin RK et al 2003. Literature reveals that causing self harm deliberately is responsible for around 600,000 deaths specifically in the developing world and is envisaged as major problem (M. Eddleston 2000):. The ironical side of chloroquine poisoning lies in the fact that it has been published in France as an effective mean of suicide and commonly used in France as well as in other countries where malaria is endemic, in suicide attempts(Clemessy JL et al 1996). The potency of chloroquine establish it as probably the king of all suicidal agent and is presented in critical overview of ways to commit suicide in the 
French book "Suicide Mode D Employ"( Phipps C 2011).

\section{CONCLUSION}

The authors detected the presence of chloroquine along with ethanol by versatile and reliable technique like HPTLC,GC-MS and GC-HS methods suitable for the rapid determination of chloroquine and ethanol in whole blood and postmortem specimen which include visceral tissue without any complex sample clean-up steps. The authors have quantified the amount of alcohol in blood along with the detection of chloroquine and such a case has not been recorded as yet to the knowledge of the authors.

\section{ACKNOWLEDGEMENTS}

The authors express their sincere gratitude to Dr. Rajendra Kumar Sarin, Former Director, Forensic Science Laboratory Govt. of NCT of Delhi, Rohini, for his support, enthusiasm and helpful comments on earlier versions of this manuscript.

\section{REFERENCES}

Adebayo RA, Sofowora GG, Onayemi O, Udoli SJ, Ajayi AA (1986): Chloroquine-induced pruritus in malaria fever: contribution of malaria parasitaemia and the effects of prednisolone, niacin, and their combination. British J Clin Pharmacol, 44, $157-161$.

Adome RO, Whyte SR, Ortenblad L, Nsabagasani $X$, Turinde AK(1997): The impact of community-based teaching on drugs: An experience from western Uganda: International conference on improving use of medicines, WHO, Essential Medicines and Policy Department.

Attimarad M, Mueen Ahmed K. K, Aldhubaib Bandar E., Harsha S (2011): High performance thin layer chromatography: A powerful analytical technique in pharmaceutical drug discovery. Pharm Methods, 2(2), 71-75.

Clemessy JL, Taboult P, Hoffman JR, Hantson P, Barriot P, Bismuth $\mathbf{C}$, Baud FJ(1996): Treatment of acute chloroquine poisoning: A 5-year experience; Crit Care Med; 24(7), 1189-1195.

Clarke, E.G.C (1974): Reagents. In Isolation and Identification of Drugs in pharmaceuticals, Body Fluids and Post-mortem Material. Vol.1 The Pharmaceutical Press, London, p 799.

Cooper RG, Magwere T (2008): Chloroquine: Novel uses \& manifestation, Indian J Med Res, 127, 305-316.

Eddleston M. (2000): Patterns and problems of deliberate self-poisoning in the developing world. Quarterly journal of Med, 93(11,715-731.

Frank W. Kiel (1964): Chloroquine Suicide; The Journal of the American Medical Association,190 (4),398-400.

Gold frank LR (1998). Gold Frank's Toxicology Emergencies.6th ed. Stamford, CN: Appleton and Lange; 745.

Ihenacho HNC, Magulike E(2008): Chloroquine abuse and heart block in Africans: Int Med J, 19,17-21.

Jaiswal A.K, Millo T, Murty O.P (2009): Thin Layer Chromatography (TLC) an important tool for forensic scientists toxicology-A review; Journal of 
Forensic Medicine and Toxicology,26(1),21-33.

Keller T, Schneider A, Lamrecht R, Aderjan R, Tutsch-Bauer E, Kisse W (1998): Fatal Chloroquine intoxication, Forensic Science International ,96,21-28.

Kugelberg FC, Jones AW (2007): Interpreting result of ethanol analysis in post-mortem specimens: A review of the literature; Forensic science international, 165,10-29.

Kumar R, Singh BS, Singh N, Singh $\mathbf{J}(\mathbf{2 0 0 5})$ : Review of management of common poisoning in India; Medico Legal Update, 5(2), 31-38.

Magwere T, Naik YS, Hasler JA(1997): Effects of chloroquine treatment on antioxidant enzymes in rat liver and kidney. Free radical Bio. Medicine, 22,321 - 327 .

Mbajiorgu Ejikeme Felix (2010): Interactions of ethanol and chloroquine in protein malnourished male Sprague Dawley Rats; Haematological, Biochemical and Testicular effects. (Submitted in the Department of Medical Science, School of Health Sciences, Faculty of Health Sciences University of Limpopo (Turfloop Campus).

Meeran K, Jacobs MG (1993): Chloroquine poisoning rapidly fatal without treatment. BMJ, 307(6895), 49-50

Mohan D, Mohandas $\mathbf{E}$ and Ray $\mathbf{R}$ (1981): Chloroquine Psychosis: A Chemical Psychosis, Journal of The National Medical Association ,73(11),1073-1076.

Muhm M, Stimpfl T, Malzer R, Mortinger $\mathrm{H}$, Binder R, Vycudilik W et al (1996): Suicidal Chloroquine Poisoning: Clinical course, Autopsy
Finding and Chemical analysis, J Forensic Sci, 41(6), 1077-1079.

Nothdurft HD, Kain KC (2017). The travel \& Tropical Medicine Manual. $5^{\text {th }}$ ed.:71-90.

Phipps C, Chan K, Ponampalam $R$ (2011): Fatal Chloroquine Poisoning: A Rare Cause of Sudden Cardiac Arrest, Annals Academy of Medicine, 40(6),296-297.

Queen HF , Tapfumaneyi C, Lewis RJ(1999): The rising incidence of serious chloroquine overdose in Harare, Zimbabwe: Emergency department surveillance in the developing world Tropical Doctor, 29,139-141.

Rao MS (2005). Toxicological Manual, Directorate of Forensic Science, Ministry of Home Affairs, Government of India, New Delhi, $1^{\text {st }}$ Edn., Selective and Scientific Books.

Rodrigues E.J, Rataboli P.V (2000): Suicidal Death due to Severe Chloroquine Overdose-A Case Report. Journal of Indian Academy of Forensic Medicine, 22 (1):1-2.

Sanchez-Chapula JA, Salinas- Stefanon E, Torres- Jacome J, BenavidesHaro DE, Navarro-Polanco RA (2001): Blockade of currents by the Antimalarial Drug Chloroquine in Feline Ventricular Myocytes, The Journal of Pharmacology \& Experimental Therapeutics, 297(1), 437-445.

Sarin R.K, Satpathy K.P, Ramteke V.B, Samikannu P, Sharma G.P (2003): Death involving ChloroquineAnalytical Aspects, Asian Journal Of Chemistry,15(1),15-18.

Smith GD, Amos TAS, Mahler R, Peters TJ (1987): Effects of chloroquine on insulin and glucose homeostasis in 
normal subjects and patients with noninsulin-dependent diabetes mellitus. Br Med J; 294: 465 - 467.

Stiff G, Robinson D, Cugnoni HL, Touquet R, Dalton AM (1991): Massive chloroquine overdose $-\mathrm{A}$ Survivor; Postgrad Med J,67, 678-679.

T.A Don Michael, S. Aiwazzadeh (1970): The effects of acute chloroquine poisoning with special reference to the heart, American Heart Journal, 79(6), 831-842.
Torrey EF (1968): Chloroquine Seizures, JAMA, 204 (10), 115-118.

www.who.int/malaria/publications/worldmalaria-report2017/report/en accessed on $26 / 08 / 2018$.

Yonemitsu K, Koreeda A, Kibayashi K, Ng'walali P, Mbonde M, Kitinya J, Tsunenari S (2005): HPLC analysis of anti-malarial agent, chloroquine in blood and tissue from forensic autopsy cases in Tanzania, Legal Medicine, 7, 113-116. 